Article

\title{
A Phenology-Based Method for Monitoring Woody and Herbaceous Vegetation in Mediterranean Forests from NDVI Time Series
}

\section{David Helman ${ }^{1, *}$, Itamar M. Lensky ${ }^{1}$, Naama Tessler ${ }^{2}$ and Yagil Osem ${ }^{3}$}

1 Department of Geography and Environment, Bar Ilan University, Ramat-Gan 5290002, Israel; E-Mail: itamar.lensky@biu.ac.il

2 Department of Biology and Environment, University of Haifa at Oranim, Kiryat Tivon 36006, Israel; E-Mail: naamates@gmail.com

3 Department of Natural Resources, Agricultural Research Organization, Volcani Center, Bet Dagan 50250, Israel; E-Mail: yagil@volcani.agri.gov.il

* Author to whom correspondence should be addressed; E-Mail: davidhelman.biu@ gmail.com; Tel.: +972-3-5318-342; Fax: +972-3-7384-033.

Academic Editors: Eileen H. Helmer, Clement Atzberger and Prasad S. Thenkabail

Received: 7 July 2015 / Accepted: 11 September 2015 / Published: 21 September 2015

\begin{abstract}
We present an efficient method for monitoring woody (i.e., evergreen) and herbaceous (i.e., ephemeral) vegetation in Mediterranean forests at a sub pixel scale from Normalized Difference Vegetation Index (NDVI) time series derived from the Moderate Resolution Imaging Spectroradiometer (MODIS). The method is based on the distinct development periods of those vegetation components. In the dry season, herbaceous vegetation is absent or completely dry in Mediterranean forests. Thus the mean NDVI in the dry season was attributed to the woody vegetation (NDVIw). A constant NDVI value was assumed for soil background during this period. In the wet season, changes in NDVI were attributed to the development of ephemeral herbaceous vegetation in the forest floor and its maximum value to the peak green cover $\left(\mathrm{NDVI}_{H}\right)$. NDVIw and $\mathrm{NDVI}_{\mathrm{H}}$ agreed well with field estimates of leaf area index and fraction of vegetation cover in two differently structured Mediterranean forests. To further assess the method's assumptions, understory NDVI was retrieved form MODIS Bidirectional Reflectance Distribution Function (BRDF) data and compared with $\mathrm{NDVI}_{\mathrm{H}}$. After calibration, leaf area index and woody and herbaceous vegetation covers were assessed for those forests. Applicability for pre- and post-fire
\end{abstract}


monitoring is presented as a potential use of this method for forest management in Mediterranean-climate regions.

Keywords: LAI; MODIS; Mt. Carmel; understory; wildfire; Yatir

\section{Introduction}

Monitoring the dynamics of different vegetation components of the forest is essential to identify and understand trends in vegetation structure and ecosystem functioning. Specifically, changes in vegetation cover from woody to herbaceous species might indicate successional processes [1] or decline/recovery processes following natural and/or anthropogenic disturbances [2,3]. Woody and herbaceous vegetation constitute different layers in forests (e.g., under and over-story layers), which makes their monitoring important for use in land-atmosphere models [4]. Moreover, practical fields such as the management of wood [5] and range [6] production, fire risk [7], wildlife habitat [8] and biodiversity [9] depend upon estimating woody and herbaceous vegetation in woodlands. For example, woody and herbaceous vegetation regulate fire behavior and fire severity in different manners [10]. They also differ in their value for livestock grazing depending on animal type (e.g., cattle and sheep consume mainly herbaceous plants while goats feed mostly on woody species).

Conventional monitoring through ground inventory surveys is costly, time consuming and limited in temporal and spatial coverage [11]. In particular, reliable long-term vegetation monitoring in Mediterranean forests is challenging, as these forests are usually unable to return their costly management and monitoring operations. Satellite remote sensing offers an efficient and accessible tool for continuous vegetation monitoring at local to global scales complementing spatio-temporal limitations of field data.

Among satellite remote sensing tools, spectral vegetation indices are widely used for monitoring vegetation [12]. However, satellite-derived vegetation indices are mostly used to interpret changes such as greening or browning of the entire vegetation system without being able to distinguish between the woody and herbaceous contribution to those trends [13-16]. To date, a few studies have used vegetation indices to detect vegetation components in woodland systems at a sub-pixel level.

Canisius and Chen [17] proposed a physical-based approach to distinguish between understory and overstory reflectance in forests using satellite images. They applied multi-angle observations of canopy reflectance to monitor changes in understory reflectance. Yang et al. [18] proposed a more empirical-based method using the Moderate Resolution Imaging Spectroradiometer (MODIS) Bidirectional Reflectance Distribution Function (BRDF) product to retrieve ecosystem understory Normalized Difference Vegetation Index (NDVIu). Although both methods successfully retrieve understory reflectance in sparse forests [19] they are unable to separate the contribution of woody and herbaceous vegetation to the understory signal.

To distinguish between woody and herbaceous contributions, Roderick et al. [20] used time series analysis on NDVI. They aimed to map woody and herbaceous cover across Australia by applying a moving average method to separate between the long inter-annual trend and the seasonal (intra-annual) components of the time series. They assumed that woody vegetation in Australia is mainly evergreen 
(i.e., woody plants that keep their leaves and stay green throughout the entire year) and herbaceous vegetation is ephemeral (i.e., above ground tissues that wither during the dry season). Then, they attributed the baseline of the trend to the woody vegetation and the seasonal signal to herbaceous vegetation in the understory [20].

Lu et al. [21] further refined their method by applying a Seasonal-Trend decomposition (STL) [22] based on LOcally wEighted regreSsion Smooth (LOESS), adding a small seasonal component to the trend. By applying STL on 8-km NDVI time series derived from the Advanced Very High Resolution Radiometer (AVHRR), they produced ensemble-monthly averages of herbaceous vegetation cover for a 14-year period over Australia. Although promising, their proposed model is relatively complex and not suited for Mediterranean vegetation systems. In their model, the NDVI attributed to the woody vegetation increases simultaneously with the NDVI attributed to the herbaceous vegetation, while in actuality there is a delay of a few months between the development of ephemeral (herbaceous) and evergreen (woody) foliage in Mediterranean systems [23].

Here we present an efficient method to distinguish between NDVI from woody (i.e., evergreen) and herbaceous (i.e., ephemeral) vegetation in Mediterranean woodlands at a sub-pixel scale using phenology-based time series analysis. We first built 14-year MODIS NDVI time series at a temporal resolution of 16 days and spatial resolution of $250 \mathrm{~m}$. Then, using the distinct phenology of the herbaceous and woody vegetation we decomposed NDVI time series into their woody (NDVIw) and herbaceous $\left(\mathrm{NDVI}_{\mathrm{H}}\right)$ signals. Results were compared with field data of overstory (i.e., woody) leaf area index and estimated woody and herbaceous vegetation covers in two Mediterranean woodlands. We also compared our results with NDVIu retrieved from MODIS BRDF data [18] at those two sites. Finally, we demonstrate the potential applications of this method for forest management and pre/post-fire monitoring.

\section{Data and Methods}

\subsection{Satellite Data and Processing}

We used the MODIS NDVI product (MOD13Q1) at a spatial resolution of $250 \mathrm{~m}$. This product is a composite based on a single day value selected from periods of 16 days using a maximum value criterion [24]. Fourteen-year time series (from September 2000 to September 2014) of 16-day NDVI were built and woody and herbaceous signals were separated using the procedure described in Section 2.3 for each pixel at two woodland sites (see Section 2.2). NDVI, the most used vegetation index, is based on the solar reflectance in the red (Red, $0.6 \mu \mathrm{m})$ and near infrared bands (NIR, $0.8 \mu \mathrm{m})$. It is normalized to get values between -1 to 1 , with fully vegetation cover approaching 1 [25]:

$$
\mathrm{NDVI}=\frac{\mathrm{NIR}-\mathrm{Red}}{\mathrm{NIR}+\mathrm{Red}}
$$

NDVI exhibits asymptotic (saturation) problems over highly dense vegetation cover and is also sensitive to canopy background variations with brighter canopies negatively biasing NDVI values over sparse vegetation [24]. However, NDVI reliably detected green biomass and vegetation dynamics in Mediterranean ecosystems that display relatively low to moderate values [26-29]. We preferred NDVI to the enhanced vegetation index (EVI), although EVI overcomes some of the above-mentioned drawbacks, because EVI tends to be much noisier over our study area with lower signal to noise ratio. 
Noise and uncertainties in NDVI time series were reduced with LOESS [30], a technique for eliminating outliers from datasets with seasonal signal [21]. LOESS was applied with a window of $\mathrm{n}=16$ time steps ( $\times 16$ days) to track the intra-annual change eliminating outliers that were greater than the standard deviation. Then, the residual was added to the smoothed time series to reproduce the original time series excluding only erroneous data. This procedure successfully eliminated cloud-contaminated and other erroneous data from the time series in all pixels within the study sites area.

To retrieve understory NDVI, we applied the method proposed by Yang et al. [18] on the MODIS BRDF/Albedo product (MCD43A1, version 5). The MCD43A1 is produced every eight days with 16 days of acquisition using data from both Terra and Aqua satellites [31]. It provides the weighting parameters associated with the RossThick-LiSparse BRDF model that describes the reflectance anisotropy at a 500m spatial resolution. The MCD43A1 product for tile h20v05 was downloaded with the associated data quality (MCD43A2) for the period of August 2005-August 2006.

The rationale behind Yang et al. [18] method is that pixels with smaller overstory LAI (LAIo) expose more understory cover making the understory contribution to the NDVI more significant. Thus NDVI in pixels with LAIo approaching 0 would be attributed mostly to the understory. Such pixels are difficult to find or even identify in forests. However, if LAIo varies between pixels, each pixel exposes different understory cover displaying distinct NDVI value. Then, the expected NDVI for LAIo $=0$ (i.e., NDVIu) could be calculated by using regression analysis on those pixels and their reconstructed NDVI values for different angles (from BRDF data). A linear regression is performed after setting the nadir-view NDVI as the independent variable and the reconstructed NDVI values from the bidirectional angles as dependent variables. NDVIu is then calculated as the mean NDVI value in which regression lines (one regression line for each angle in the pixels of a defined window) have the smallest standard deviation. Correlations should be significant for pixels within a defined window with a similar canopy structure but variable LAIo. For the full description of this method and some illustrative examples the reader is referred to [18].

Here, we chose a window of $3 \times 3$ pixels following the criteria established by Yang et al. (see Section 5.2 in [18]). A 16-day NDVIu time series was produced for each one of the two case study sites. It is worth noting that NDVIu includes the combined signal from evergreen woody vegetation and ephemeral herbaceous plants in the understory. Therefore, NDVIu should be comparable to soil background NDVI (0.1-0.2) in Yatir during the dry season. This is because there is hardly any evergreen vegetation in the understory and the herbaceous vegetation is completely dry (see Section 2.2.1). Hence, comparable NDVIu and ecosystem NDVI values during the wet season in Yatir would imply that the herbaceous vegetation is the main contributor to the NDVI during this period assessing the method's assumptions (see Section 2.3). At Mt. Carmel, NDVIu is expected to be higher than soil NDVI during the dry season due to evergreen woody species in the understory (see Section 2.2.2.).

\subsection{The Case Study Sites}

\subsubsection{Yatir Pine Forest}

The Yatir forest is a pine forest (Pinus halepensis) planted mostly from 1964 to 1969 in the semiarid region of Israel $\left(31^{\circ} 20^{\prime} 49.2^{\prime \prime} \mathrm{N}, 35^{\circ} 03^{\prime} 07.2^{\prime \prime} \mathrm{E}\right.$, Figure 1a). It covers an area of 2800 ha (Figure 1b). The 
average elevation is $650 \mathrm{~m}$ a.s.l. and mean annual precipitation is $285 \mathrm{~mm} \cdot \mathrm{yr}^{-1}$ (for the last 40 years). The mean annual temperature is $18.2{ }^{\circ} \mathrm{C}$ with 13 and $31{ }^{\circ} \mathrm{C}$ for mean winter (November-January) and summer (May-July) temperatures, respectively. Tree density is $\sim 300$ trees $^{\prime} \mathrm{ha}^{-1}$ with a mean tree diameter of $17.5 \mathrm{~cm}$ and mean tree height of $11 \mathrm{~m} \mathrm{[32].} \mathrm{The} \mathrm{canopy} \mathrm{leaf} \mathrm{area} \mathrm{index} \mathrm{(LAI)} \mathrm{is} \mathrm{typically}$ $\sim 1.4 \pm 0.4 \mathrm{~m}^{2} \cdot \mathrm{m}^{-2}$ with small fluctuations between winter and summer [33]. The understory is comprised of ephemeral herbaceous species (i.e., theropytes, geophytes and hemicryptophytes) growing during the wet season (September-April) and drying out in the beginning of the dry season (May-June). A relatively thin needle litter layer covers the forest floor during the needle senescence period (June-August) [23]. The forest understory is absent of evergreen vegetation (Figure 1c).
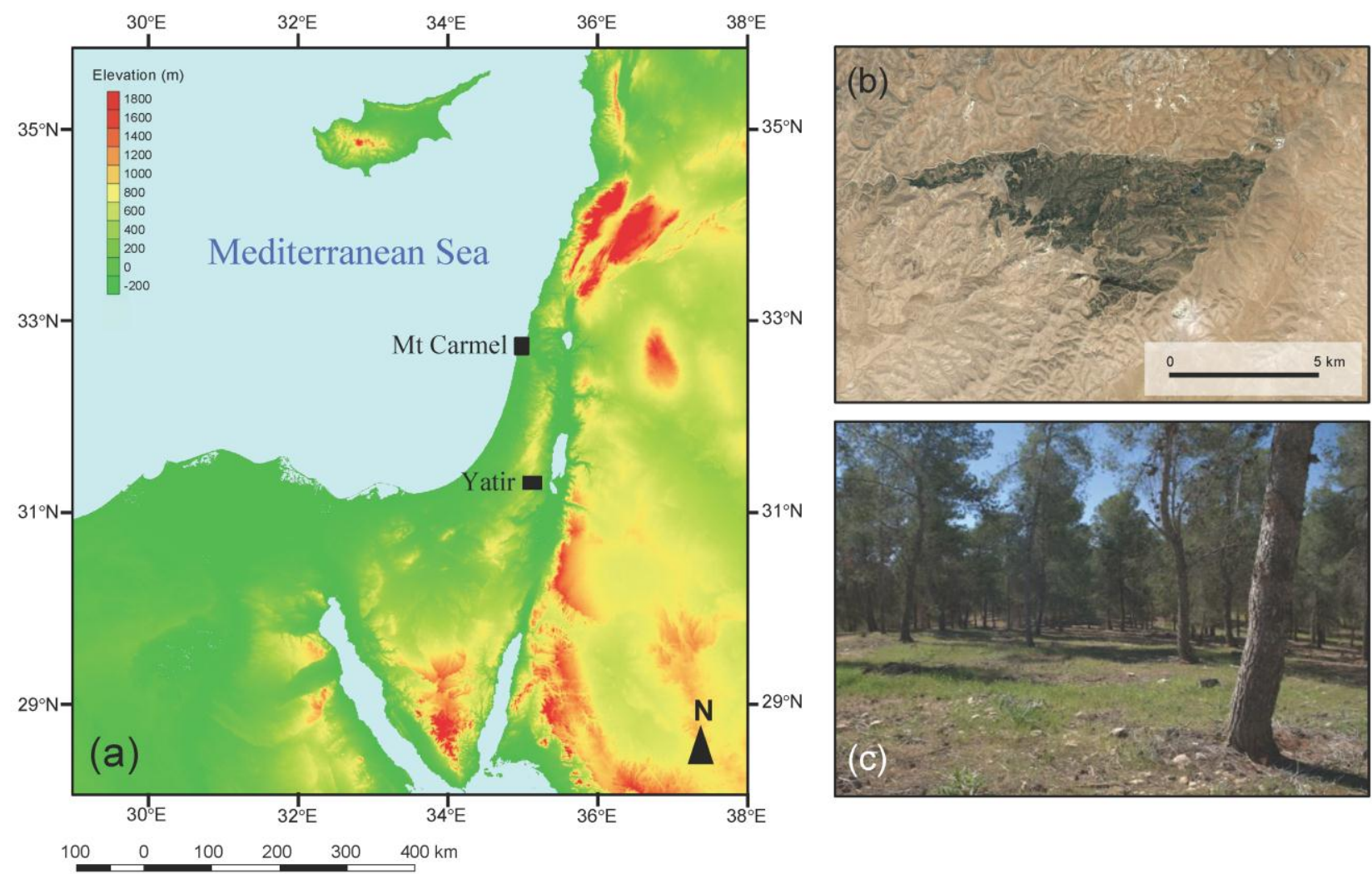

Figure 1. (a) Location of the two study sites (Yatir forest and Mt. Carmel woodlands). (b) Aerial (Google Earth ${ }^{\circledR}$ ) and (c) field views of the planted pine forest of Yatir in the semiarid region of Israel. Photo: Eugene Ivanov.

This forest site was selected because it has only two vertical layers (i.e., evergreen trees in the overstory and ephemeral herbaceous species in the understory) and a monospecific single-aged stand structure, which makes easier interpretation of the results. Moreover, this site was subject to extensive studies since the operation of its FLUXNET station in 2000 and is of special interest for its contribution, along other semi-arid ecosystems, to the climate system [34,35].

We used allometric mean annual LAIo estimates for the period of January 2000-June 2005 and monthly effective LAIo measured using a TRAC device (Tracing Radiation and Architecture of Canopies) during 2005 and 2006, both from Sprintsin et al. [33], to calibrate and compare with NDVIw (i.e., overstory trees in the case of Yatir). 


\subsubsection{Mt. Carmel Mixed Pine-Oak Woodlands}

Mt. Carmel region $\left(35^{\circ} \mathrm{E}, 32^{\circ} \mathrm{N} ; 10-520 \mathrm{~m}\right.$, Figure 1a) has a typical East-Mediterranean climate with dry hot summers (June-August) and cool rainy autumns and winters (October-May). The mixed pine-oak woodlands in Mt. Carmel cover an area of $\sim 21,500$ ha (Figure 2a). Mean annual precipitation ranges from $550 \mathrm{~mm} \cdot \mathrm{yr}^{-1}$ near the coastal plane to $750 \mathrm{~mm} \cdot \mathrm{yr}^{-1}$ at the highest elevations (550 $\mathrm{m}$ a.s.1.). Vegetation in Mt. Carmel varies between dense multi-aged mixed pine-oak woodland and a more open and patchy shrublands. It consists of a variety of woody shrub and tree species in which the most dominant are Pinus halepensis, Quercus calliprinos, Pistacia lentiscus L. and Cistus salviifolius L., along with a large variety of herbaceous species (i.e., therophytes, geophytes and hemicryptophytes). This results in a complex vertical and horizontal multi-strata canopy structure [36] (Figure 2b).
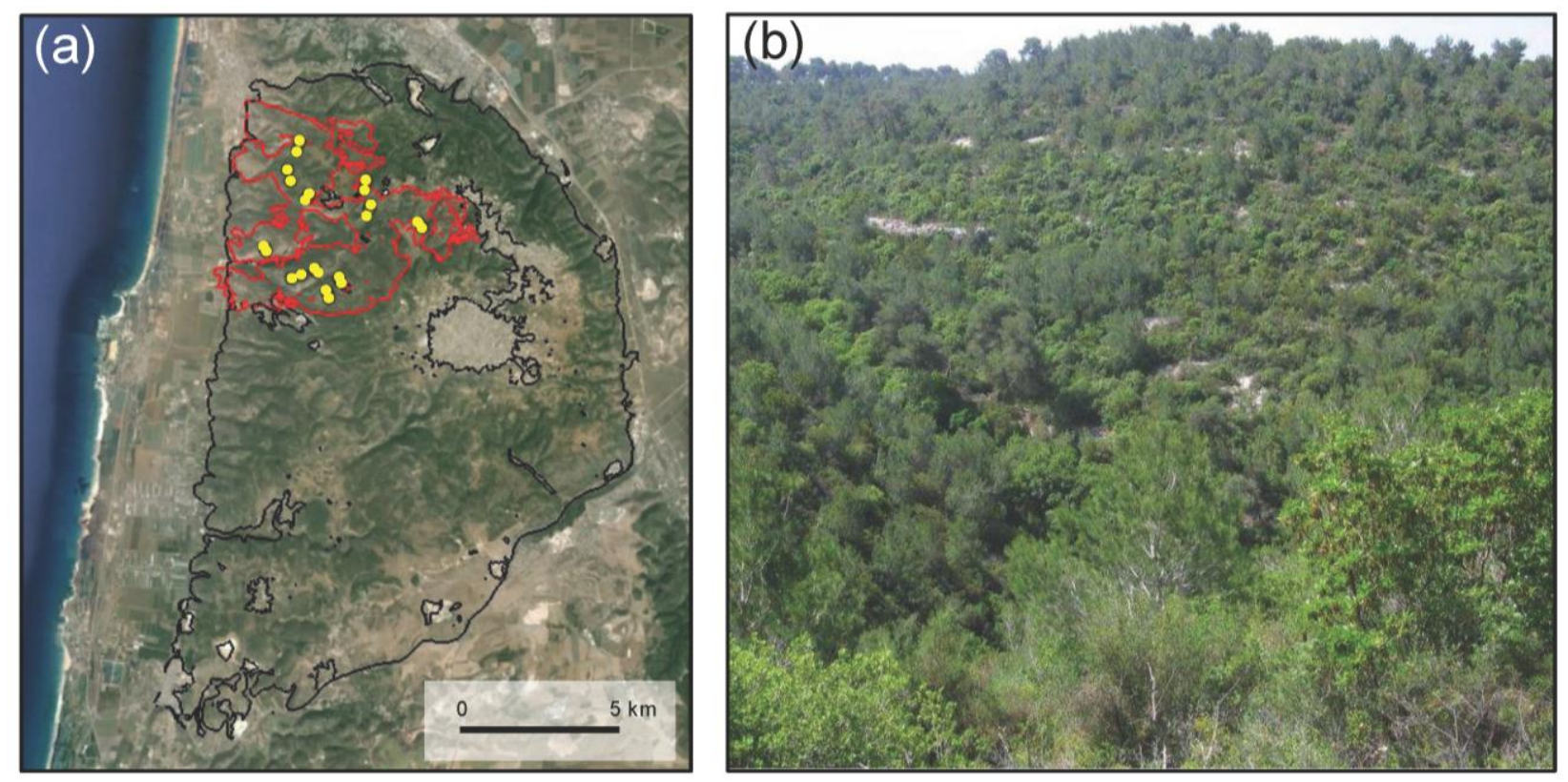

Figure 2. (a) Aerial (Google Earth ${ }^{\circledR}$ ) and (b) field views of the mixed pine-oak evergreen woodlands at Mt. Carmel. The burnt area from the wildfire of 2010 (red line) and the location of the 22 survey plots (dots) are indicated in (a). Photo: Naama Tessler.

The most dominant tree species are the Aleppo Pine (P. halepensis) and the common oak (Quercus calliprinos). These two evergreen tree species vary strongly in their total cover and shift in dominance depending on ecological site conditions (mainly bedrock type), land use history (grazing, cutting), and disturbances (fire). Herbaceous plants in the understory are all ephemerals with a life cycle during the wet season. The area went through repeated fires during the last 20 years affecting the regeneration of $P$. halepensis, which resulted in multi-aged pine distribution [37]. Wildfires in this site changed the forest structure and ratio of woody to herbaceous vegetation cover affecting its hydrological balance and ecosystem functioning [38].

We selected this site to test our method in a more complex woodland system comprising evergreen woody vegetation in the understory. In addition, this area went through a large wildfire ( $2500 \mathrm{ha})$ in December 2010 [39] and was monitored since then providing in situ data of vegetation cover that can be 
used to compare with our results. This site represents a typical complex-structured Mediterranean woodland system with relatively high productivity (unpublished data).

Four field surveys were conducted since the wildfire of 2010 during the spring seasons (March-May, i.e., the time of peak herbaceous cover) of 2011-2014 in 22 plots of $10 \times 10 \mathrm{~m}^{2}$ each. The plots were selected based on Mt. Carmel geology map on southern and northern aspects within the burnt area (Figure 2a). In each plot, total vegetation cover and specific species cover were determined following Stohlgren [40]. Species cover were summed and grouped into three groups: evergreen trees in the overstory $(T r-E v)$, evergreen shrubs in the understory $(S h-E v)$ and ephemeral herbaceous plants in the understory (He-Ep) (Table 1). In addition to vegetation cover assessment, fire severity was determined in each plot and classified as: low, medium and high according to the classification proposed by Neary et al. [41]. Classification was extended to the total burnt area by using high spatial resolution aerial photos and GIS tools.

Table 1. The mean vegetation cover (\%) of evergreen trees $(T r-E v)$ and shrubs $(S h-E v)$ and ephemeral herbaceous species (He-Ep) estimated in 22 plots at Mt. Carmel (Figure 2a) during 2011-2014. The total vegetation cover in each plot, and the mean and standard errors (SE) of all plots are also indicated.

\begin{tabular}{|c|c|c|c|c|}
\hline Plot & $\operatorname{Tr}$-Ev (over) & $S h-E v$ (under) & $H e-E p$ (under) & Total (over + under) \\
\hline 1 & 14 & 37 & 17 & 68 \\
\hline 2 & 9 & 38 & 33 & 80 \\
\hline 3 & 2 & 39 & 44 & 85 \\
\hline 4 & 3 & 25 & 59 & 87 \\
\hline 5 & 12 & 41 & 30 & 83 \\
\hline 6 & 28 & 41 & 16 & 85 \\
\hline 7 & 15 & 30 & 30 & 77 \\
\hline 8 & 17 & 46 & 18 & 82 \\
\hline 9 & 16 & 29 & 23 & 68 \\
\hline 10 & 16 & 34 & 20 & 70 \\
\hline 11 & 9 & 53 & 26 & 88 \\
\hline 12 & 19 & 28 & 30 & 77 \\
\hline 13 & 20 & 31 & 23 & 73 \\
\hline 14 & 9 & 17 & 35 & 60 \\
\hline 15 & 14 & 29 & 26 & 68 \\
\hline 16 & 25 & 38 & 20 & 83 \\
\hline 17 & 31 & 26 & 36 & 93 \\
\hline 18 & 13 & 24 & 29 & 67 \\
\hline 19 & 28 & 25 & 15 & 68 \\
\hline 20 & 14 & 49 & 18 & 80 \\
\hline 21 & 29 & 18 & 31 & 78 \\
\hline 22 & 28 & 46 & 11 & 85 \\
\hline AVG & 17 & 34 & 27 & 78 \\
\hline SE & 2 & 2 & 2 & 2 \\
\hline
\end{tabular}

Average in situ vegetation cover for each plot were used to calibrate NDVIw and NDVI $\mathrm{H}_{\mathrm{H}}$, and to produce woody and herbaceous cover maps for 2000-2014 at Mt. Carmel. NDVI $\mathrm{H}_{\mathrm{H}}$ was regressed against 
$H e-E p$, while NDVIw was regressed against the sum of $T r-E v$ and $S h-E v$ covers. Calibrations included only 14 MODIS pixels $(250 \mathrm{~m})$ because some of the 22 plots were within the area of a single pixel. In such case, species covers were averaged to get the mean cover within the pixel area. Plots that fall between pixels were discarded.

Although there are some uncertainties when comparing field and satellite data due to scaling and/or sensor view issues [42], this method has been extensively used to calibrate/validate satellite vegetation indices with biophysical parameters $[21,26,27,43]$. To test the robustness of this calibration we calculated vegetation covers using the classical two-end members fractional vegetation cover equation [44]:

$$
\mathrm{FVC}=\frac{\mathrm{NDVI}_{\mathrm{X}}-\mathrm{NDVI}_{0}}{\mathrm{NDVI}_{\mathrm{Full}}-\mathrm{NDVI}_{0}}
$$

where NDVI 0 in Equation (2) is the NDVI from the soil background (0.1), NDVIFull is the NDVI from a fully vegetated area ( 0.7 and 0.9 for woody and herbaceous, respectively) and NDVIx is the NDVIw or the NDVIH value. Finally, we compared woody and herbaceous cover maps retrieved from the two models.

\subsection{Description of the Method}

The well-defined wet and dry seasons characterizing Mediterranean climate regulate the photosynthetic activity and growth of the vegetation in Mediterranean ecosystems [45]. The seasonal year in Mediterranean forests is defined as the 12-month period since the beginning of the rainfall in October [32]. Ephemeral herbaceous species appear as an understory layer in forests shortly after the beginning of the rainy season (October-November) reaching a peak biomass at the end of winter (February), drying out in spring (April) [46]. In contrast, the evergreen woody vegetation becomes most active from early spring (March) developing new leaves towards the dry season (June-August) [23] (Figure 3).

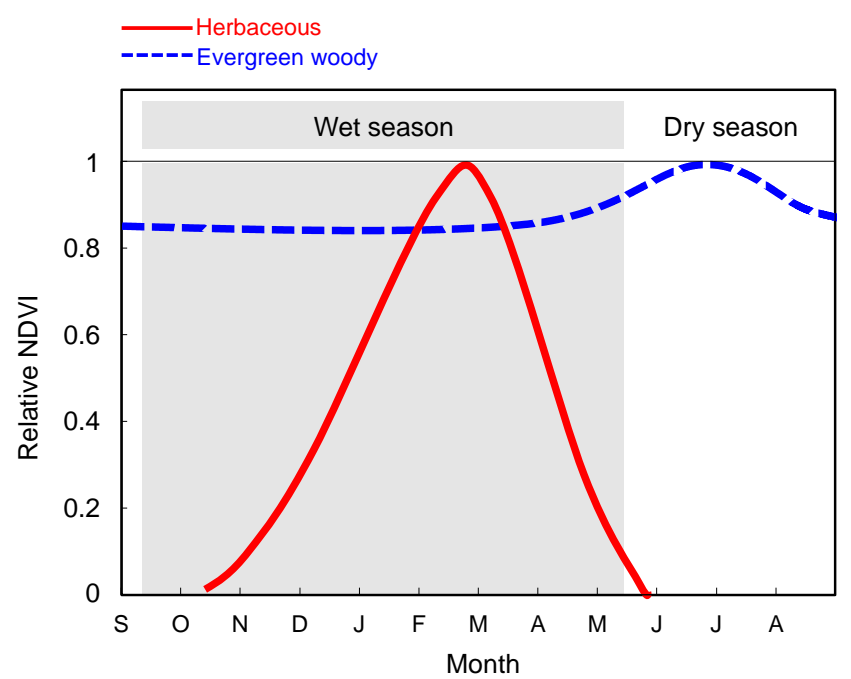

Figure 3. Schematic representation of the distinct growth and senescence periods of evergreen woody vegetation (dashed blue line) and ephemeral herbaceous plants (red line) in Mediterranean forests. Phenological stages are shown as the relative Normalized Difference Vegetation Index (i.e., NDVI/NDVI $\max$ ) of each of those two vegetation components. The wet and dry periods are also indicated. 
These two components, i.e., woody and herbaceous species, contribute differently to the NDVI (Figure 3) resulting in a mixed signal at the sub pixel scale $[19,20]$. Hence, only by using time series analysis the contribution of these components to the total ecosystem NDVI (NDVIEcos) can be estimated. Because in Mediterranean woodlands the herbaceous vegetation is mostly ephemeral, NDVIEcos during the dry season (June-August) could be attributed solely to evergreen woody species and soil background (hereafter NDVIw). Then, the seasonal component (i.e., the NDVIEcos in wet season-October-April) would be attributed mostly to the herbaceous vegetation (hereafter NDVIseas), which is the most dynamic component (in terms of NDVI) in those systems [21]. Accordingly, we separated the woody and herbaceous NDVI from the NDVIEcos in three steps:

(1) The average NDVIEcos over the dry period (June-August) was calculated and taken as NDVIw for each seasonal year (i.e., from September to September). If NDVIEcos in the wet season was lower than the calculated NDVIw, the minimum NDVIEcos value was taken as the NDVIw instead. This ensures that abrupt intra-annual changes following disturbances (e.g., fires or clearing) are detected. For example, if a fire event occurs in December (i.e., during the wet season), taking the average NDVIEcos over the dry season (June-August) would overestimate woody cover in that specific year. In contrast, taking the minimum NDVIEcos, which is the NDVIEcos value following the fire, would be more representative because it includes the change due to the fire.

(2) The NDVIw is then subtracted from NDVIEcos to compute the seasonal component of the time series (NDVIseas).

(3) The maximum NDVIseas value in each seasonal year is taken as $\mathrm{NDVI}_{\mathrm{H}}$, which represents the peak biomass/green-cover of the herbaceous vegetation [13].

By assuming a constant NDVI for soil background during the dry season [27], NDVIw could be used to track inter-annual changes in forest's woody cover or leaf area index (LAI) after calibrating against ground truth data. Similarly, $\mathrm{NDVI}_{H}$ could be used to monitor changes in green biomass [26,27] or herbaceous vegetation fraction cover [20,21].

Although $\mathrm{NDVI}_{\mathrm{H}}$ does not account for herbaceous vegetation fully covered by the canopy, it is assumed that in closed forests it contributes a negligible fraction due to the limited light resource [21]. In open forests, though, because sensor view angle changes throughout the year, $\mathrm{NDVI}_{\mathrm{H}}$ is assumed to represent almost all of the herbaceous vegetation present in the forest floor. The validity of these assumptions were previously demonstrated in several studies $[21,26,27]$ and will be further examined here by comparing with field data and the calculated understory NDVI (NDVIu) from the MODIS BRDF data [18].

\subsection{Applications of NDVI $I_{W}$ and $N D V I_{H}$ for Pre- and Post-Fire Monitoring in Mt. Carmel}

We demonstrate three pre/post fire-monitoring applications using NDVIw and NDVI $\mathrm{H}$ in Mt. Carmel woodlands selecting the wildfire of 2010 as a case study. Field data collected at the burnt area (described in Section 2.2.2) were compared with three applications of NDVIw and $\mathrm{NDVI}_{\mathrm{H}}$

(i) Post-fire monitoring of woody and herbaceous recovery (i.e., changes in woody and herbaceous cover) in the burnt area of the wildfire of 2010 (four post-fire years) assessed from NDVIw and NDVI $\mathrm{H}_{\mathrm{H}}$ 
(ii) Fire severity assessment in the burnt area from the difference in NDVIw between pre and post fire years.

(iii) Production of a fuel-based fire risk map from NDVIw for the year prior to the wildfire and comparison with fire-spread behavior (i.e., the burnt area). Fire risk map was produced by assigning a relative score from 1 to 10 (i.e., from the lowest to the highest risk level) to each pixel in the Mt. Carmel area according to its woody cover (i.e., 1 for minimum and 10 for maximum cover) and dryness status (i.e., 1 for the most positive, or no trend, and 10 for the most negative trend).

Although forest fires are driven also by weather conditions, topography and many other factors, here we examined the importance of fuel density and status on fire spread behavior. This is important because fire hazard models mostly use static fuel-based maps that does not account for long-term drought effects on the woody vegetation status. We did not use NDVIн in this map because fires in Mt. Carmel were mostly driven by woody dry matter and less by ephemeral herbaceous vegetation [47]. Moreover, the fire risk map produced when using also NDVIH was mostly similar to that produced from NDVIw alone.

\section{Results and Discussion}

\subsection{Mapping Leaf Area Index from NDVIW in Yatir}

Figure 4a shows the time series of NDVI of the entire ecosystem (NDVIEcos) from 2000 to 2014 (from September to September) in one representative pixel at the planted pine-forest of Yatir. The NDVIEcos during the summer was relatively low $(\sim 0.3)$ increasing in winter, reaching a maximum value of $0.45-0.6$ and decreasing afterward towards the next summer (Figure 4a). NDVIw generally increased from 2001 (i.e., the seasonal year of 2000/1) to 2008 decreasing afterward till the end of the time series (Figure 4c).

NDVISeas was very dynamic throughout the years in Yatir (Figure 4e) probably due to variations in annual rainfall amount [26]. The NDVIu derived from BRDF data was almost the same as the NDVIEcos during the main wet season (November-April, Figure 5a). Because understory vegetation in Yatir is comprised mostly of ephemeral herbaceous species, this supports the assumption that herbaceous vegetation in the understory is the main contributor to the seasonal change in NDVIEcos. However,

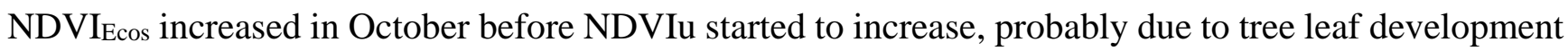
as observed from the increase in LAIo (Figure 5a). Similarly, NDVIEcos was higher than NDVIu during the senescence period (March-April) coincident with an increase in LAIo (Figure 5a).

The relatively high NDVIu during the summer ( 0.23) compared to the soil background NDVI for this region (0.1-0.2) was probably due to accumulated greenish to yellowish needle litter in the understory, which is typically accumulated during this period in the forest floor [23]. $\mathrm{NDVI}_{\mathrm{H}}$ showed almost an opposite trend to NDVIw mostly decreasing till 2009, increasing in the following years (Figure 4g). The relationship between LAIo from the TRAC measurements and June to August NDVIEcos was significant $\left(\mathrm{R}^{2}=0.72, p<0.05\right.$, Figure $\left.5 \mathrm{~b}\right)$. NDVIw also agreed well with in situ mean annual LAIo during January 2000-June $2005\left(\mathrm{R}^{2}=0.71, p<0.05\right)$, exhibiting a typical exponential relationship $\left(\mathrm{LAI}=0.18 \cdot e^{7 \cdot \mathrm{NDVI}_{\mathrm{P}}}\right.$, Figure $\left.5 \mathrm{c}\right)$. Indeed, the significant relationships between NDVI and in situ LAIo imply that the mean over the dry season NDVIEcos (i.e., NDVIw) is a good estimator of the mean annual LAIo in this forest site. 
(a)

(c)
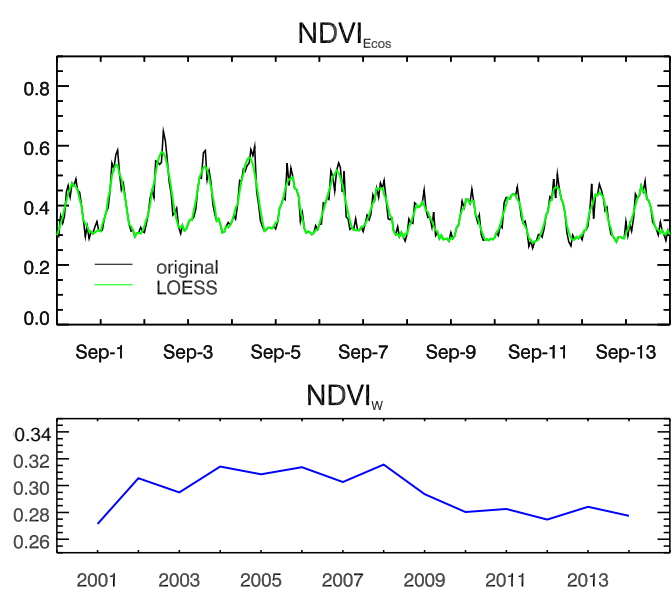

(e)

(g)

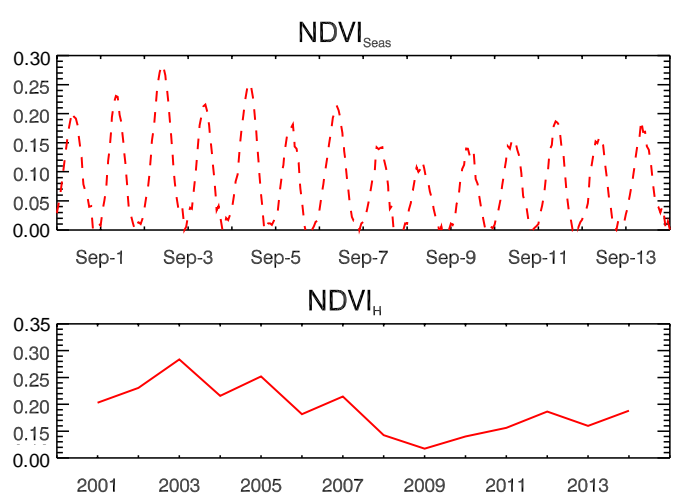

(b)

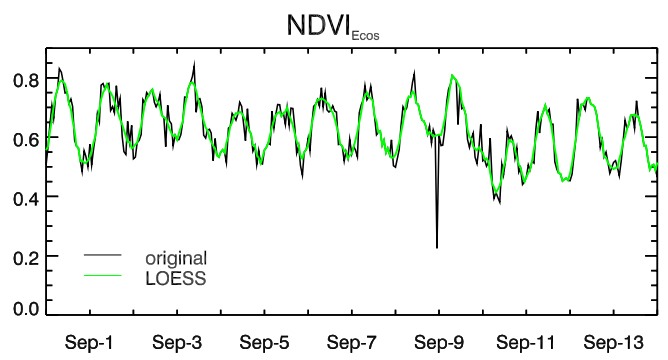

(d)

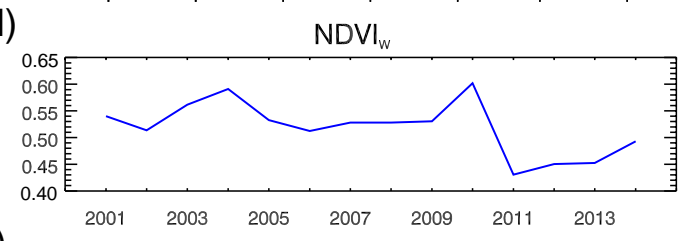

(f)

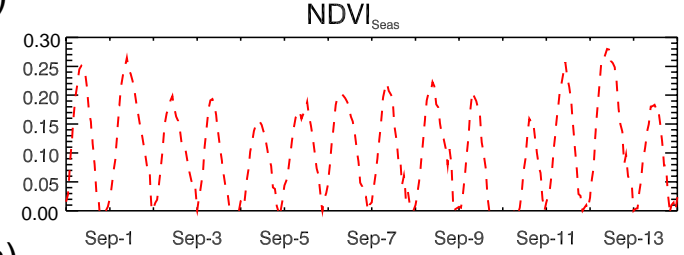

(h)

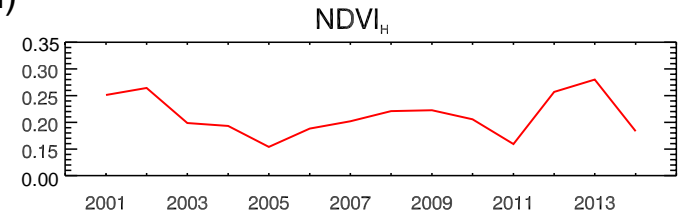

Figure 4. Examples of the original and decomposed NDVI time series in one representative pixel $(250 \mathrm{~m})$ at the evergreen pine forest of Yatir (left column) and the pine-oak woodlands of Mt. Carmel (right column). Original and smoothed time series of NDVIEcos are shown in (a,b), NDVIw in (c,d), NDVIseas in (e,f) and NDVIH in (g,h) for Yatir and Mt. Carmel, respectively.

(a)

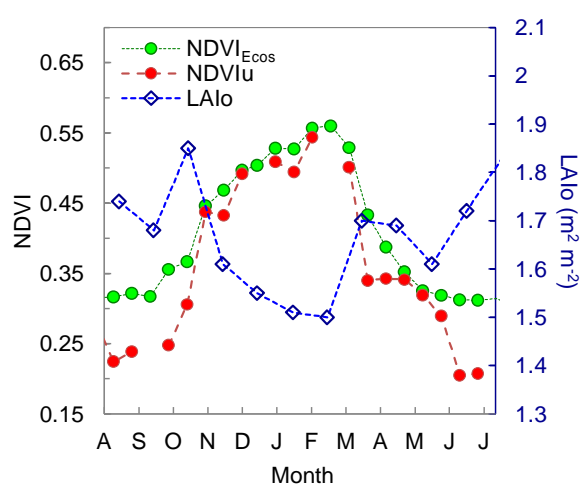

(b)

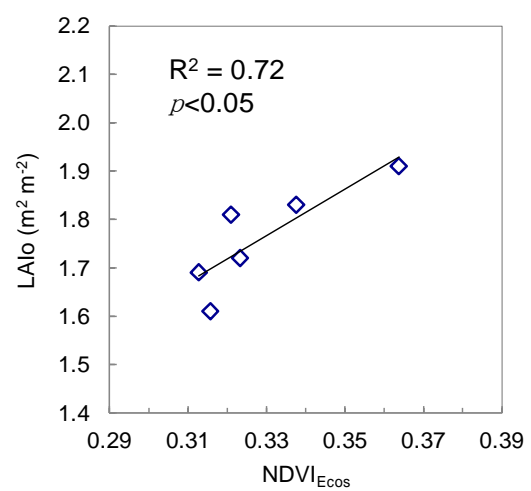

(c)

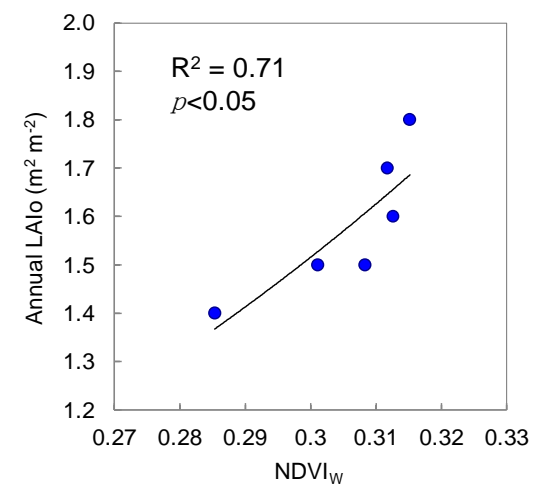

Figure 5. (a) NDVIEcos, NDVIu (retrieved from Bidirectional Reflectance Distribution Function product), and monthly in situ overstory LAI (LAIo) in a $4 \mathrm{~km}^{2}$ area at the Yatir pine forest. Scatterplots showing the relationships between (b) monthly LAIo vs. NDVIEcos and (c) mean annual LAIo vs. NDVIw (2000-2006) for the same area.

Figure 6 shows the spatial distribution of the mean annual LAIo calculated from NDVIw in Yatir at a $250 \mathrm{~m}$ spatial resolution with mostly negative trends for the period of 2000-2014. 
(a)

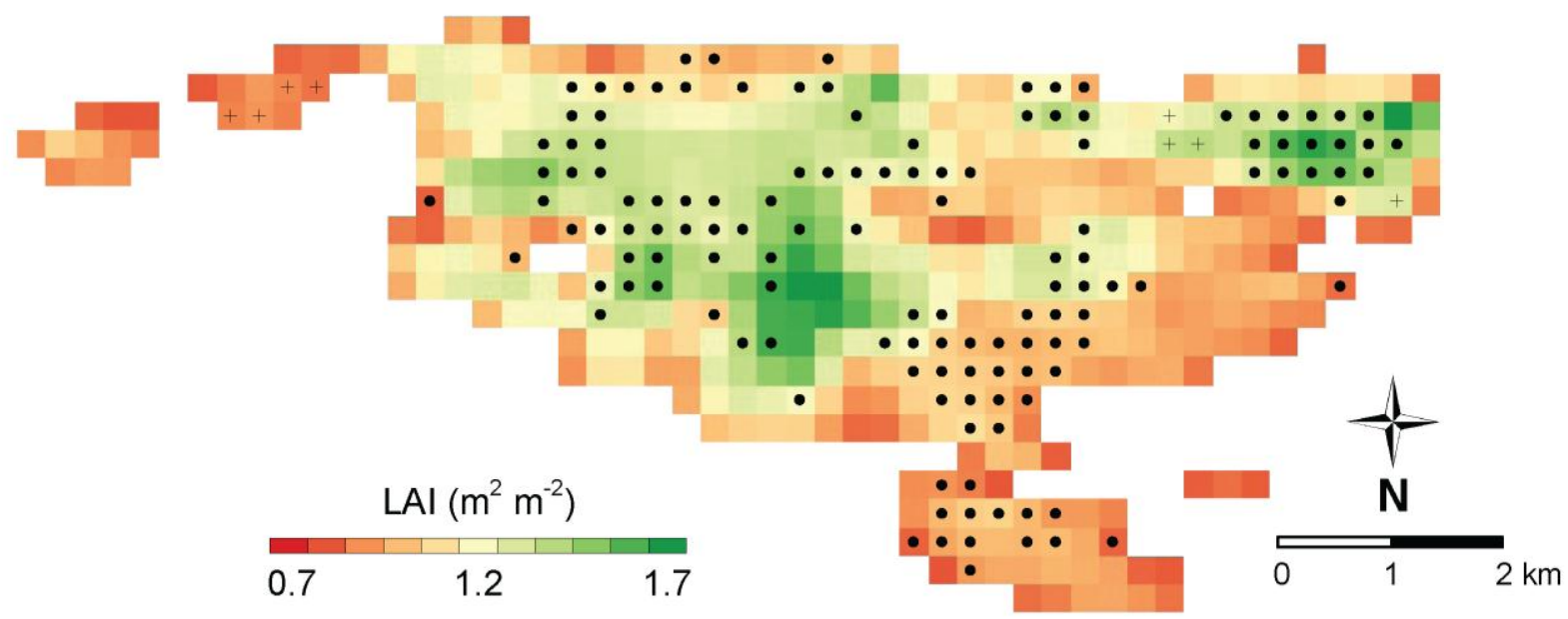

(b)

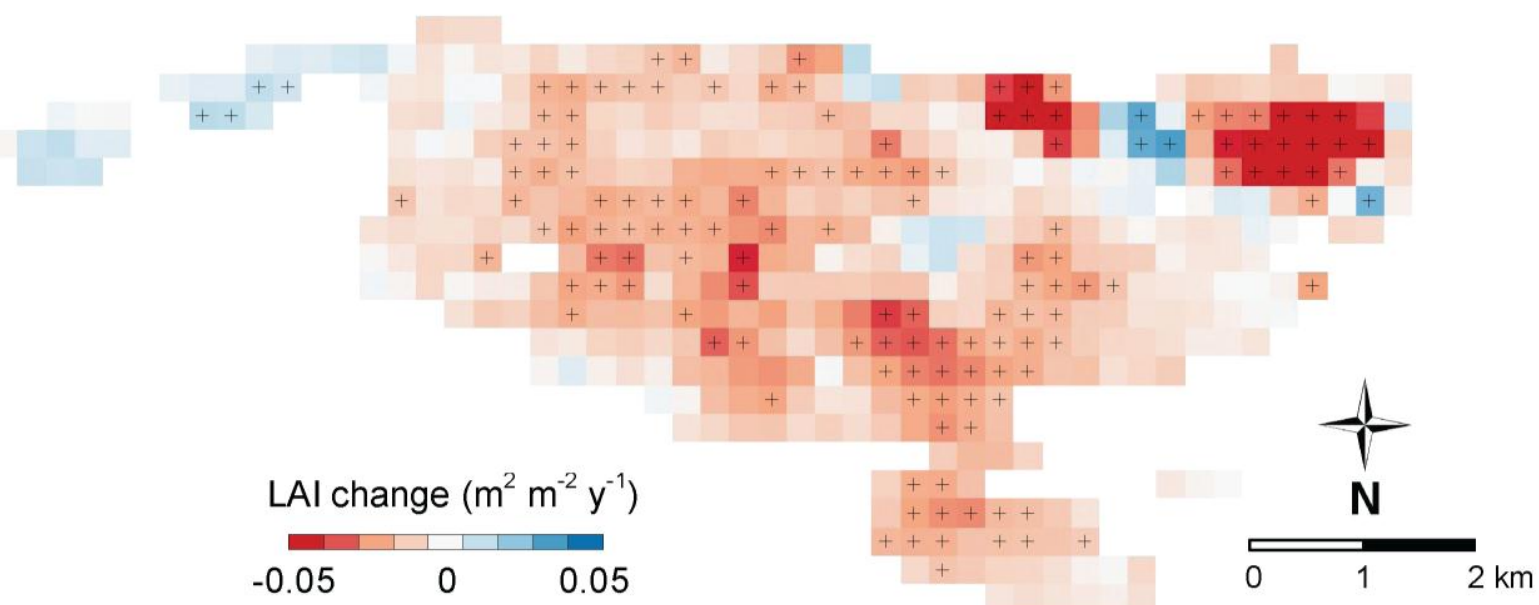

Figure 6. Spatial distribution of (a) the mean annual and (b) trends of overstory LAI retrieved from NDVIw at Yatir for 2000-2014. Significant trends are indicated in (a) as + (positive) and - (negative), while in (b) all significant trends are indicated as + .

\subsection{Assessing Woody and Herbaceous Cover from NDVIW and NDVI $\mathrm{N}_{\mathrm{H}} \mathrm{Mt}$. Carmel}

Figure 4b,d,f,h show the NDVIEcos and its decomposition into NDVIw, NDVIH and NDVIseas in one representative pixel at the mixed pine-oak woodlands of Mt. Carmel. The large wildfire of December 2010 (2500 ha) is noted by an abrupt decline in NDVIw from 2010 to 2011 (Figure 4d). Another, much smaller wildfire event in 2005 (150 ha, [39]) is also noted by a decrease in NDVIw from 2004 to 2005. As in Yatir, the NDVIu retrieved from BRDF data suggests that understory vegetation is the primary contributor to NDVIEcos during the wet season (November-April, Figure 7). However, unlike in Yatir, the NDVIu was high in Mt. Carmel woodlands during the dry season $(\sim 0.4)$ due to the relatively dense evergreen vegetation cover in the understory. 


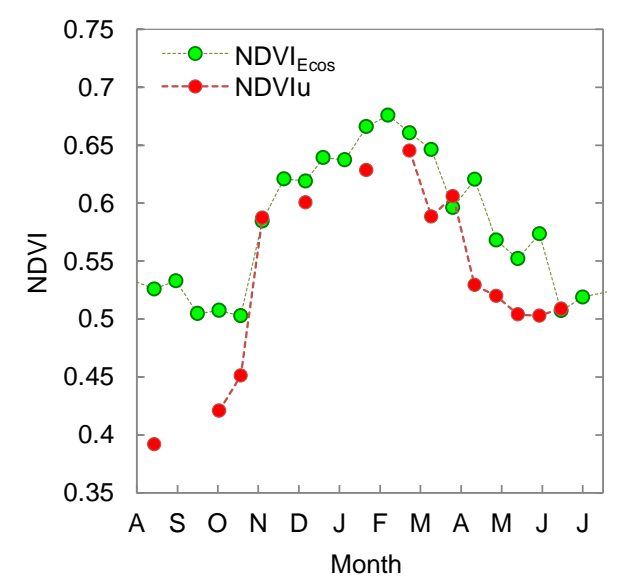

Figure 7. NDVIEcos and NDVIu (from BRDF) in a 4- $\mathrm{km}^{2}$ area of the pine-oak woodlands at Mt. Carmel.

Woody and herbaceous vegetation covers estimated in field were significantly correlated with NDVIw and NDVI $\mathrm{H}_{\mathrm{H}}$, respectively ( $p<0.01$ for both, Figure 8). The coefficient of determination was moderate with $\mathrm{R}^{2}$ of 0.58 for NDVIw $v s$. woody cover and 0.69 for $\mathrm{NDVI}_{H} v s$. herbaceous vegetation cover. Correlations were only moderate probably due to the scale differences between the field plots $\left(10 \times 10 \mathrm{~m}^{2}\right)$ and the MODIS pixels $\left(250 \times 250 \mathrm{~m}^{2}\right)$.
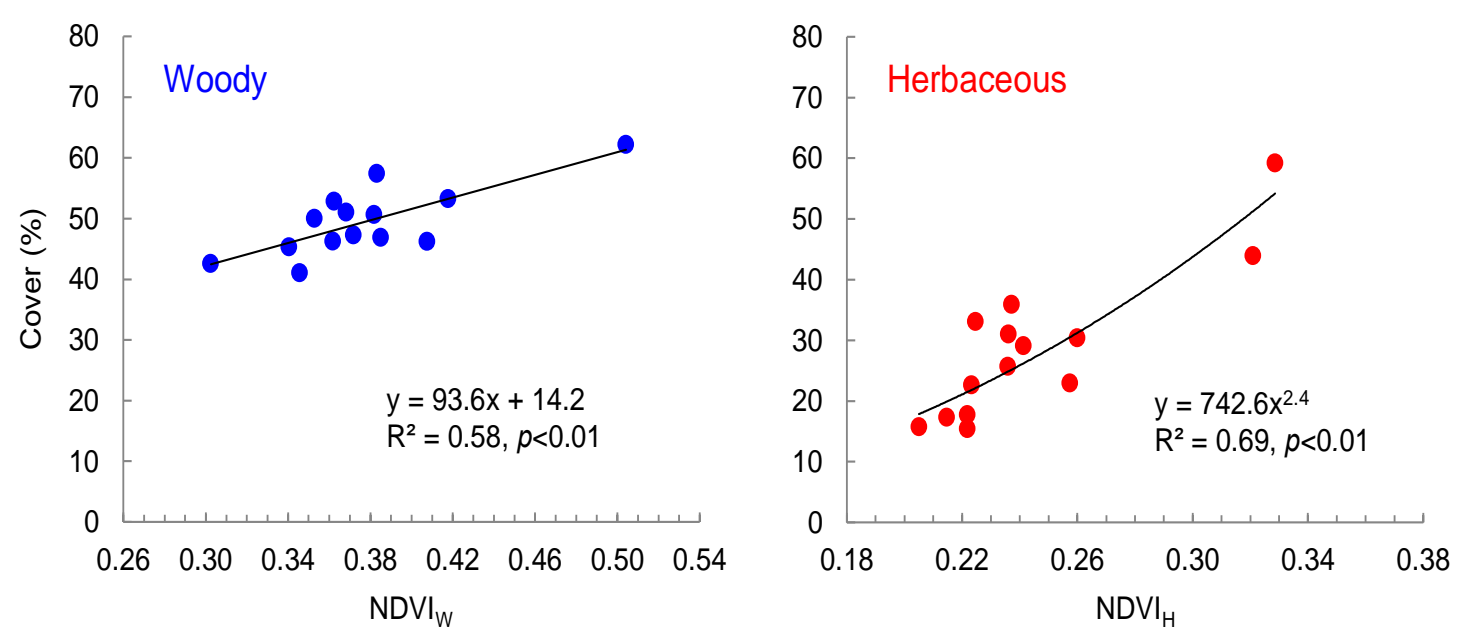

Figure 8. Scatterplots of woody (left) and herbaceous (right) vegetation covers (\%) assessed in field $v s$. NDVIw and $\mathrm{NDVI}_{\mathrm{H}}$ in 14-MODIS pixels. Each dot in the graph is the four-year averaged vegetation cover within one MODIS pixel (see Section 2.2.2). For the herbaceous vegetation cover, an exponential function was fitted following the assumption that $\mathrm{NDVI}_{\mathrm{H}}$ equals 0 in the dry season when herbaceous vegetation is absent ( $0 \%$ cover).

We used the regression functions from Figure 8 to derive maps of the mean annual woody and herbaceous vegetation covers at Mt. Carmel for the period of 2000-2014 (Figure 9a,d). Similar spatial patterns with slightly different magnitudes were obtained from NDVIw and $\mathrm{NDVI}_{H}$ when using the two-end members FVC equation (Equation (2), Figure 9b,e). 
(a)

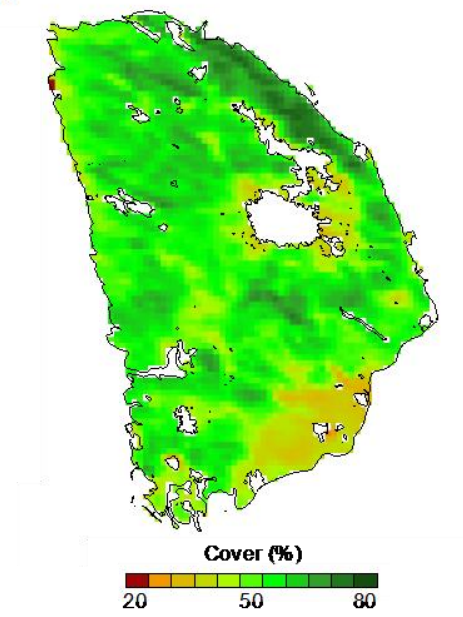

(d)
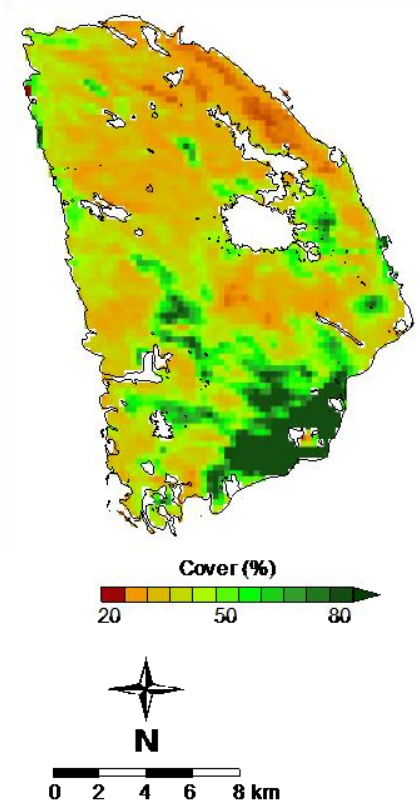

(b)

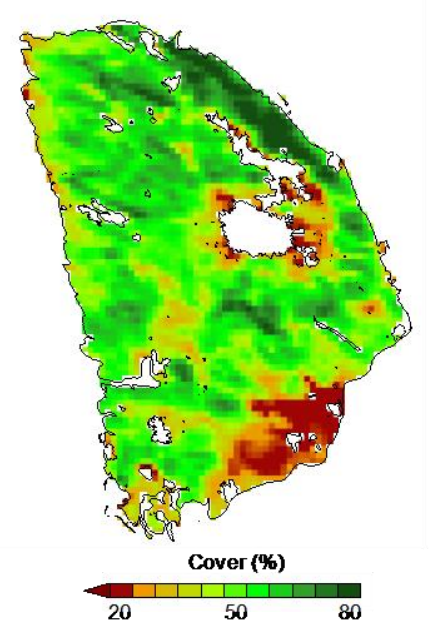

(e)

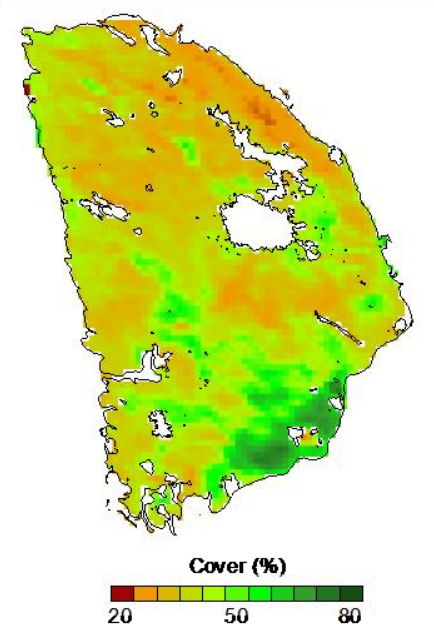

(f)

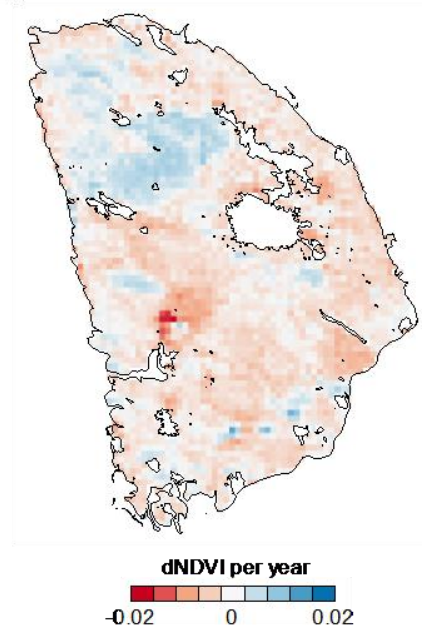

Figure 9. The 14-year mean woody $(\mathbf{a}-\mathbf{c})$ and herbaceous $(\mathbf{d}-\mathbf{f})$ vegetation cover $(\%)$ and NDVI trends in Mt. Carmel. Vegetation cover was estimated from NDVIw and NDVIH using $(\mathbf{a}, \mathbf{d})$ NDVI-field regression functions (see Figure 8$)$ and $(\mathbf{b}, \mathbf{e})$ the two-end members FVC equation (Equation (2)). The strong NDVIw decline in (c) and contrast NDVIH increase in (f) are the result of the 2010 wildfire (compare with wildfire area in Figure 2a).

However, the range in woody cover at Mt. Carmel was narrower when using the calibration function (30\%-70\%, Figure 9a) compared to the obtained from the two-end members function $(15 \%-80 \%$, Figure $9 \mathrm{~b}$ ). This was probably because of the relatively narrow range of woody covers estimated at field and used for the calibration (40\%-60\%, Figure 8). Omitting low and high covers from the calibration resulted in overestimation and underestimation of the woody cover at sparse/dense woody cover, respectively.

Oppositely, the range of herbaceous cover was wider when using the calibration function (20\%-90\%, Figure 9d) compared to the retrieved from the two-end members function (30\%-65\%, Figure 9e). This is probably because of the exponential function used for calibration, whereas the function used in two-end 
members model is linear. Therefore, the two-end members model underestimated the herbaceous vegetation cover at low and high values of vegetation covers.

NDVIw and $\mathrm{NDVI}_{\mathrm{H}}$ were useful in assessing woody and herbaceous vegetation dynamics relatively, although the described discrepancies. A good example is the effect of the 2010 wildfire on the woody and herbaceous trends observed in Figure 9c,f. A large decline in NDVIw is clearly noted in the 14-year NDVIw trends $\left(\sim 0.2\right.$ per decade), while $\mathrm{NDVI}_{\mathrm{H}}$ slightly increased $(<0.1$ per decade) during the same period.

\subsection{Pre and Post Fire Assessment Using NDVIW and NDVIH in Mt. Carmel}

NDVI is an indicator of the vegetation dryness [48] and could be used to assess dry woody vegetation matter, which is the main fuel source in Mediterranean forest wildfires. A decline in NDVIw would imply drying trends in woody vegetation and increasing dry matter for potential fires [47]. On the contrary, low woody cover would reduce fire vulnerability in woodlands because there is less fuel for fire. Ephemeral herbaceous vegetation plays only a minor role in Mt. Carmel wildfires because of its relatively low biomass.

Figure 10a shows that the fuel-based fire risk map based only on the mean annual and trends in NDVIw reproduced the fire-spread behavior of the 2010 wildfire with great accuracy.
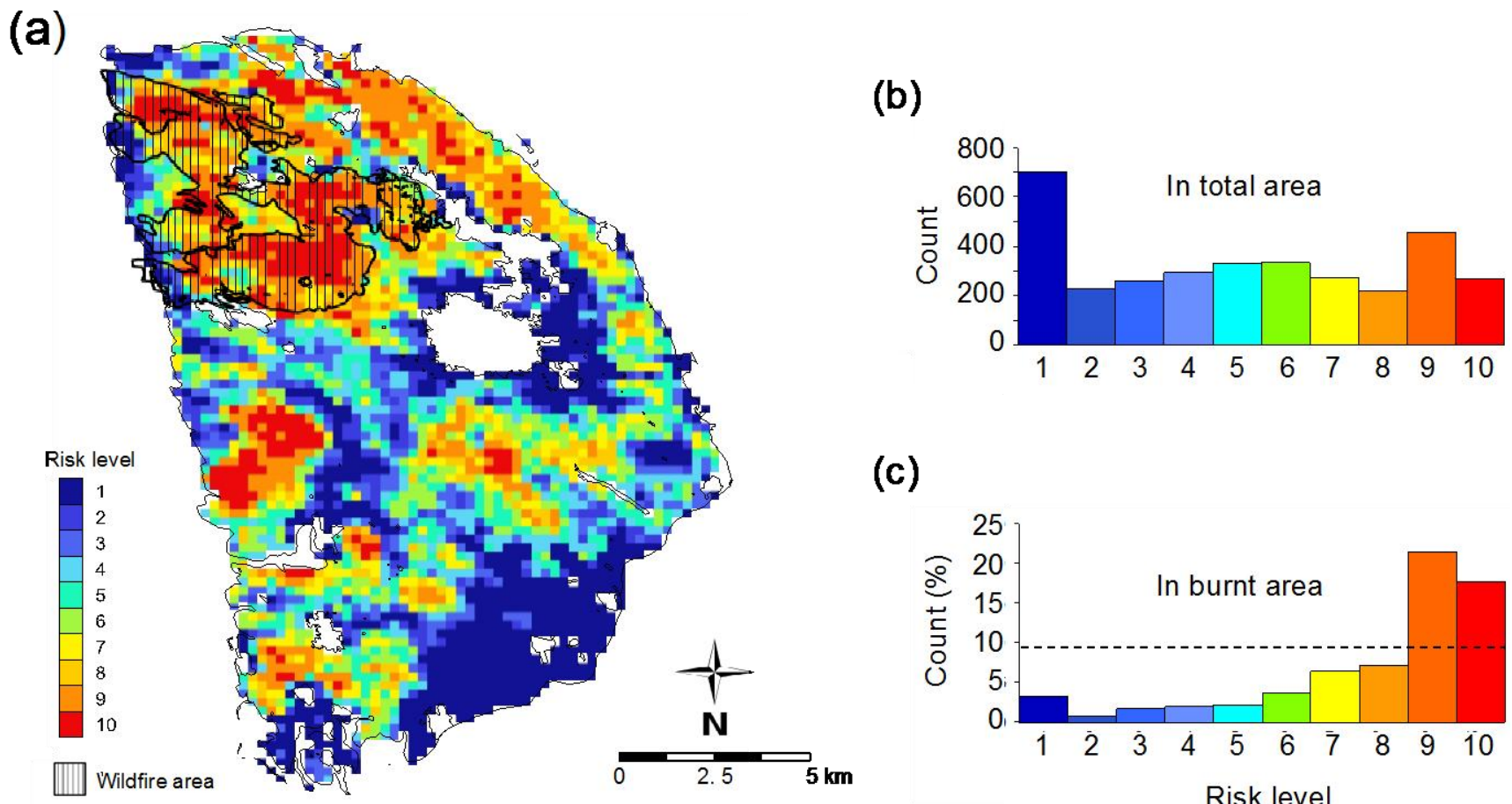

(c)

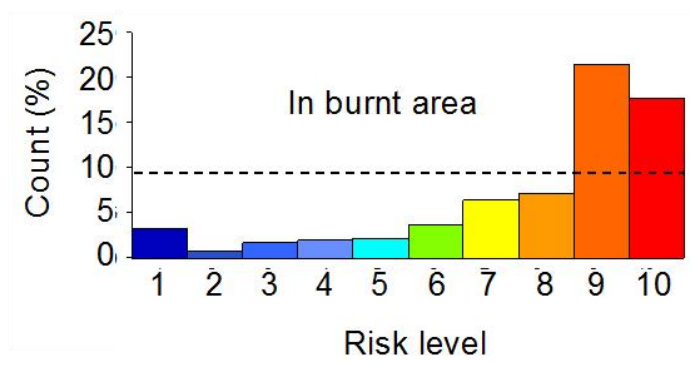

Figure 10. (a) A fuel-based fire risk map produced for the year 2009 (prior to the 2010 wildfire) from the woody vegetation cover (mean NDVIw) and its dryness status (NDVIw trends). Superimposed is the area of the wildfire; histograms of (b) the total number of pixels in Mt. Carmel with their respective risk levels and (c) the ratio between the number of pixels with a specific risk level in the burnt zone to that in the entire Mt. Carmel area (in \%). The dashed line in (c) indicates the percent area of burnt zone from the entire Mt. Carmel area (i.e., 8.6\%). 
Most of the pixels within the wildfire area were ranked with the highest risk level, being $18 \%$ and $21 \%$ (for levels 9 and 10, respectively) from the total cells ranked with the same levels in Mt. Carmel (Figure 10c). This is more than the expected in the burnt zone, which comprises only $~ 9 \%$ of the entire Mt. Carmel area. These results, based only on fuel density and status (both from NDVIw), do not consider topographic or weather conditions, which are important driving forces of fire spread behavior. However, such a fuel-based map might improve fire hazard models that mostly rely upon static fuel maps [47]. Those do not consider the effects of drought years on the woody (and/or herbaceous in other cases) vegetation status, which is an important factor determining fire spread behavior as shown here.

(a)

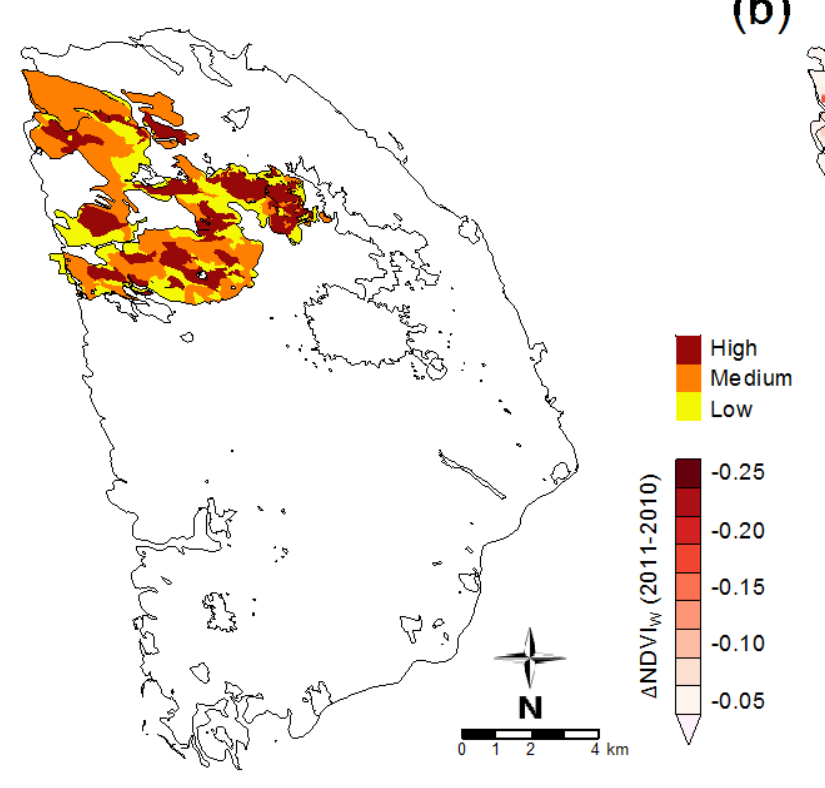

(b)

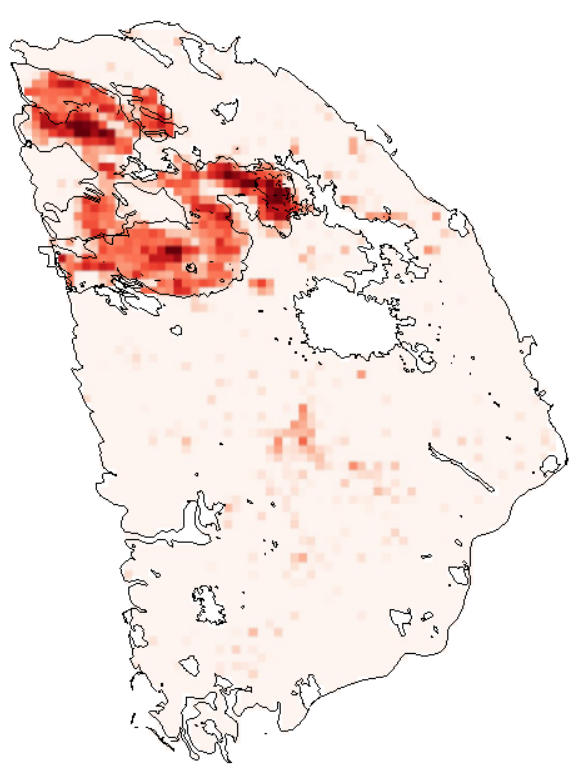

(c)

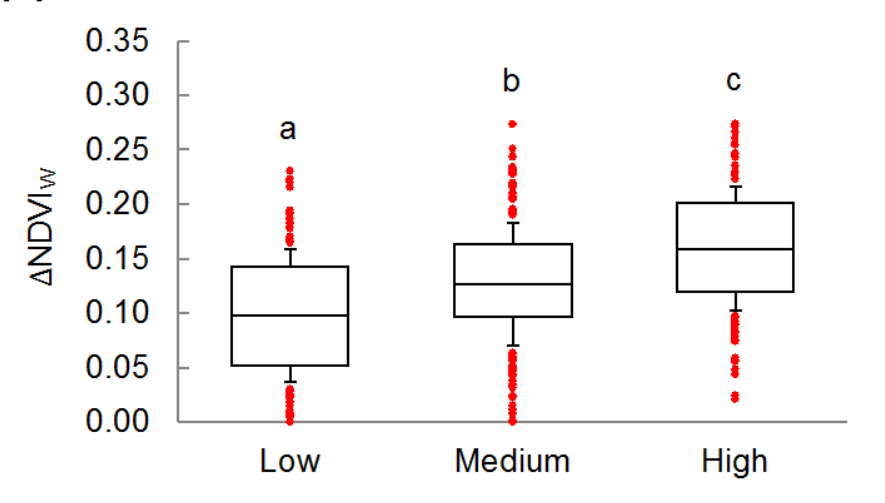

Figure 11. Maps of (a) low, medium and high severity burnt areas classified in field and extended with high-resolution aerial photograph; and (b) the difference between post- and pre-fire NDVIw $(\triangle N D V I w)$. (c) Box plot of mean, first and third quartiles (with respective standard deviations) of $\triangle \mathrm{NDVI}$ in the low, medium and high severity areas mapped at field (shown in a). Different letters indicate statistically significant differences at $p<0.001$ using a two-tailed Student's t-test, after a Bonferroni correction.

NDVIw was also used to assess fire severity in the burnt area of Mt. Carmel. Figure 11 shows the difference between NDVIw from the year prior (2010) and posterior (2011) to the wildfire ( $\triangle$ NDVIw, 
Figure $11 b)$. The mean $\triangle$ NDVIw was significantly different $(p<0.001)$ between areas classified in field as low, medium and high severity with mean $\triangle$ NDVIw of $0.1,0.13$ and 0.16 , respectively (Figure 11c).

Finally, we used NDVIw and $\mathrm{NDVI}_{\mathrm{H}}$ to assess woody and herbaceous vegetation recovery (i.e., changes in cover) in the burnt area (Figure 12). Results from NDVIw and NDVI agreed well with the field estimates when using both, the empirical relationships (from Figure 8) and the classical two-end members equation (Equation (2)). All estimates showed that after a woody cover reduction due to the wildfire (Figures 9c and 11b), woody vegetation cover decreased from 2011 to 2012 (from the year after the wildfire to the next year) but increased in the subsequent two years (Figure 12).
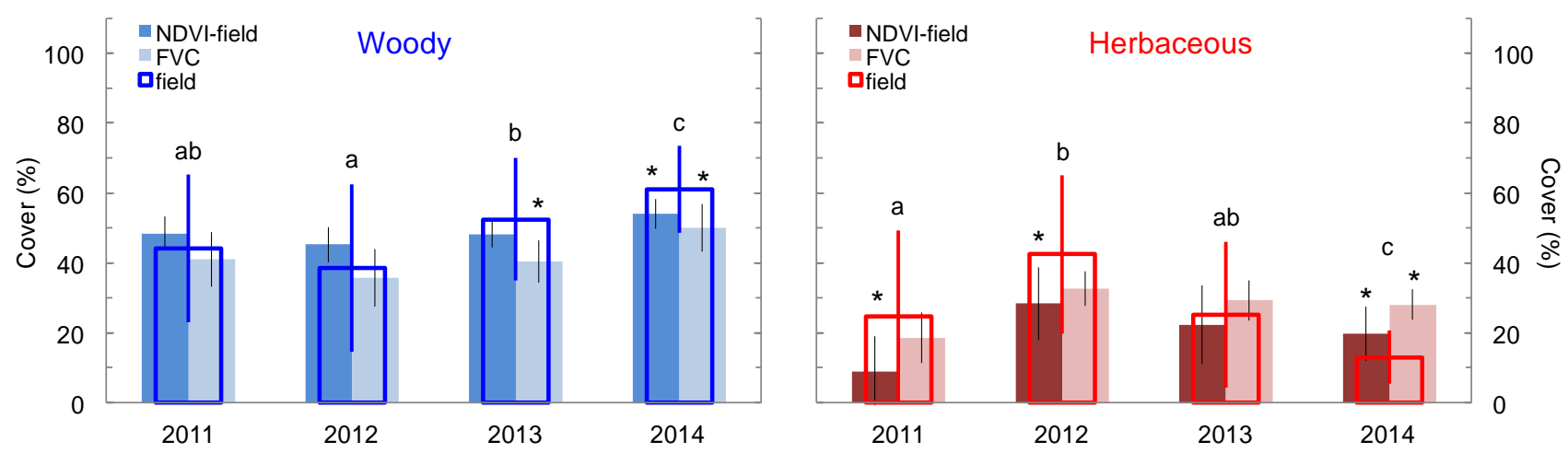

Figure 12. Changes in woody and herbaceous vegetation cover following the wildfire of 2010 as estimated from field (open bars) and from NDVI (solid bars) using a field-based calibration function (NDVI-field) and two-end members fraction of vegetation cover (FVC) equation. Asterisks indicate statistically significant differences between the NDVI's components and the field estimates for each specific year at $p<0.05$. Different letters denote statistically significant differences in vegetation covers between years at $p<0.05$.

The herbaceous vegetation cover that generally increased in the burnt zone (Figure 9f), showed an opposite change to the woody cover. It first increased from 2011 to 2012 (first to second year after the wildfire) but decreased afterward during the next two years (in 2013 and 2014).

The agreement between field estimates and calculated vegetation covers from NDVIw and $\mathrm{NDVI}_{\mathrm{H}}$ demonstrate the potential use of this method to monitor succession processes in forests following disturbances.

\section{Conclusions}

In this study, we proposed a phenology-based method that uses the distinct timing of ephemeral herbaceous (i.e, above ground tissues that wither during the dry season) and woody (i.e., evergreen) foliage development to separate time series of the Normalized Difference Vegetation Index (NDVI) into their respective contributions. The average NDVI during the dry season (i.e., when herbaceous species are dry or absent) was attributed to the woody vegetation (NDVIw), while the maximum value during the wet season $\left(\mathrm{NDVI}_{\mathrm{H}}\right)$ was attributed to the herbaceous vegetation after subtracting NDVIw from the time series. The assumption that the herbaceous vegetation contributes most of the NDVI signal during the wet season was validated with the understory NDVI (NDVIu) retrieved from an independent semi-empirical method based on the small bidirectional variation in NDVIu compared to the canopy-level variation [18]. 
Both methods showed that change in NDVI during the wet season were caused by the development of herbaceous vegetation at the understory.

NDVIw agreed well with the in situ monthly and mean annual overstory LAI (LAIo) measured at the planted pine forest of Yatir (southern Israel). The coefficients of determination $\left(\mathrm{R}^{2}\right)$ were 0.72 and 0.71 for monthly and annual LAIo, respectively. NDVIw and NDVI $\mathrm{N}_{\mathrm{H}}$ were also moderately correlated to woody and herbaceous vegetation covers estimated at field in Mt. Carmel pine-oak woodlands (northern Israel) with $\mathrm{R}^{2}$ of 0.58 and 0.69 , respectively ( $p<0.1$ for both correlations). The relationships between NDVIw and LAIo were used to assess spatial variations in mean annual and trends in LAIo at Yatir for 2000-2014. The relationships between NDVIw/NDVI ${ }_{H}$ and in situ woody/herbaceous covers were used to produce maps of mean annual and trends in woody and herbaceous vegetation covers at Mt. Carmel for 2000-2014 (using the calibration functions). The spatial patterns of those maps were comparable to those retrieved using a simple two-end members equation.

To show the potential use of this method, we presented three pre/post-fire applications using the Mt. Carmel 2010 wildfire as a case study: (1) We produced a fuel-based fire risk map with mean NDVIw representing woody cover and its trend woody dryness condition (i.e., negative trends meaning drying trends). Pixels with high NDVIw and negative NDVIw trends were ranked as high fire-risk pixels and vice-versa. The fire risk map reproduced fire-spread behavior of the wildfire of 2010 with great accuracy. About 39\% of the pixels in Mt. Carmel with the highest risk levels were found within the area of the wildfire, which constitute only 9\% from the entire Mt. Carmel area; (2) We used the difference in NDVIw between the year after and before the wildfire $(\triangle N D V I w)$ to map fire severity. The mean $\triangle$ NDVIw was significantly different $(p<0.001)$ between areas classified at field as low, medium and high severity with, respectively, decreasing $\triangle$ NDVIw values; (3) We used NDVIw and NDVIH to monitor the recovery of the woody and herbaceous vegetation in the burnt area during post-fire years (2011-2014).

The proposed method has the potentials to be used in Mediterranean systems for several forest management, fire risk assessment and post fire monitoring purposes. Moreover, it could be used to assess overstory and understory LAI and fraction of absorbed photosynthetic active radiation (fPAR) [49], which are essential parameters in land surface modeling. Yet, it should be noted that limitations of satellite imaging in detecting understory vegetation underneath a denser overstory cover $(>80 \%)$ must be further determined. This could be done, for example, by placing ground spectral sensors at several heights in the forest to determine over- and under-story NDVI [50] and compare with NDVIw and NDVIH.

Once established, this method holds a great potential for monitoring, understanding and managing complex vegetation systems comprising various combinations of woody and herbaceous vegetation in Mediterranean ecosystems.

\section{Acknowledgments}

Personal grants provided by the Ministry of Agriculture and Rural Development, the Hydrological Service of Israel, and Rieger Foundation, USA are acknowledged by David Helman. Authors are grateful to four anonymous reviewers for their valuable comments and suggestions that helped improve the former version of this manuscript. We also thank Israel Nature and Parks Authority for aiding in field surveys and NASA for making available this valuable data from MODIS satellites. 


\section{Author Contributions}

David Helman conceived and designed the experiments, analyzed the data and wrote the manuscript. Itamar M. Lensky and Yagil Osem provided guidance and contributed to the discussion. Naama Tessler provided the field data from Mt. Carmel. Itamar M. Lensky, Yagil Osem and Naama Tessler participated in writing the manuscript.

\section{Conflicts of Interest}

The authors declare no conflict of interest.

\section{References}

1. Kuebbing, S.E.; Souza, L.; Sanders, N.J. Effects of co-occurring non-native invasive plant species on old-field succession. For. Ecol. Manage. 2014, 324, 196-204.

2. Kambatuku, J.R.; Cramer, M.D.; Ward, D. Savanna tree-grass competition is modified by substrate type and herbivory. J. Veg. Sci. 2011, 22, 225-237.

3. Odion, D.C.; Moritz, M.A.; DellaSala, D.A. Alternative community states maintained by fire in the Klamath Mountains, USA. J. Ecol. 2010, 98, 96-105.

4. Pauwels, V.R.N.; Wood, E.F. A soil-vegetation-atmosphere transfer scheme for the modeling of water and energy balance processes in high latitudes: 1. Model improvements. J. Geophys. Res. Atmos. 1999, 104, 27811-27822.

5. Birdsey, R.; Pregitzer, K.; Lucier, A. Forest carbon management in the United States. J. Environ. Qual. 2006, 35, 1461-1469.

6. Nilsson, M.-C.; Wardle, D.A. Understory vegetation as a forest ecosystem driver: Evidence from the northern Swedish boreal forest. Front. Ecol. Environ. 2005, 3, 421-428.

7. Penman, T.D.; Collins, L.; Syphard, A.D.; Keeley, J.E.; Bradstock, R.A. Influence of fuels, weather and the built environment on the exposure of property to wildfire. PLoS One 2014, 9, e111414.

8. Swatantran, A.; Dubayah, R.; Goetz, S.; Hofton, M.; Betts, M.G.; Sun, M.; Simard, M.; Holmes, R. Mapping migratory bird prevalence using remote sensing data fusion. PLoS One 2012, 7, e28922.

9. Osem, Y.; Perevolotsky, A.; Kigel, J. Grazing effect on diversity of annual plant communities in a semi arid rangeland: Interactions with small scale spatial and temporal variation in primary productivity. J. Ecol. 2002, 90, 936-946.

10. Jenkins, M.J.; Page, W.G.; Hebertson, E.G.; Alexander, M.E. Fuels and fire behavior dynamics in bark beetle-attacked forests in Western North America and implications for fire management. For. Ecol. Manage. 2012, 275, 23-34.

11. Mussery, A.; Helman, D.; Leu, S.; Budovsky, A. Modeling herbaceous productivity considering tree-grass interactions in drylands savannah: The case study of Yatir farm in the Negev drylands. $J$. Arid Environ. 2016, 124, 160-164.

12. Huete, A.R. Vegetation indices, remote sensing and forest monitoring. Geogr. Compass 2012, 6, 513-532.

13. Vicente-Serrano, S.; Cabello, D.; Tomás-Burguera, M.; Martín-Hernández, N.; Beguería, S.; Azorin-Molina, C.; Kenawy, A. Drought variability and land degradation in semiarid regions: 
Assessment using remote sensing data and drought indices (1982-2011). Remote Sens. 2015, 7, 4391-4423.

14. Zhou, Y.; Zhang, L.; Fensholt, R.; Wang, K.; Vitkovskaya, I.; Tian, F. Climate contributions to vegetation variations in central Asian drylands: Pre- and post-USSR collapse. Remote Sens. 2015, 7, 2449-2470.

15. De Jong, R.; Verbesselt, J.; Schaepman, M.E.; de Bruin, S. Trend changes in global greening and browning: Contribution of short-term trends to longer-term change. Glob. Chang. Biol. 2012, 18, 642-655.

16. Erasmi, S.; Schucknecht, A.; Barbosa, M.; Matschullat, J. Vegetation greenness in northeastern brazil and its relation to ENSO warm events. Remote Sens. 2014, 6, 3041-3058.

17. Canisius, F.; Chen, J.M. Retrieving forest background reflectance in a boreal region from Multi-angle Imaging SpectroRadiometer (MISR) data. Remote Sens. Environ. 2007, 107, 312-321.

18. Yang, W.; Kobayashi, H.; Suzuki, R.; Nasahara, K.N. A simple method for retrieving understory NDVI in sparse needleleaf forests in Alaska using MODIS BRDF data. Remote Sens. 2014, 6, 11936-11955.

19. Pisek, J.; Rautiainen, M.; Nikopensius, M.; Raabe, K. Estimation of seasonal dynamics of understory NDVI in northern forests using MODIS BRDF data: Semi-empirical versus physically-based approach. Remote Sens. Environ. 2015, 163, 42-47.

20. Roderick, M.L.; Noble, I.R.; Cridland, S.W. Estimating woody and herbaceous vegetation cover from time series satellite observations. Glob. Ecol. Biogeogr. 1999, 8, 501-508.

21. Lu, H.; Raupach, M.R.; McVicar, T.R.; Barrett, D.J. Decomposition of vegetation cover into woody and herbaceous components using AVHRR NDVI time series. Remote Sens. Environ. 2003, 86, 1-18.

22. Cleveland, R.; Cleveland, W.; Mcrae, J.; Terpenning, I. STL: A seasonal-trend decomposition procedure based on loess (with discussion). J. Off. Stat. 1990, 6, 3-73.

23. Maseyk, K.S.; Lin, T.; Rotenberg, E.; Grünzweig, J.M.; Schwartz, A.; Yakir, D. Physiology-phenology interactions in a productive semi-arid pine forest. New Phytol. 2008, 178, 603-616.

24. Huete, A.; Didan, K.; Miura, T.; Rodriguez, E.P.; Gao, X.; Ferreira, L.G. Overview of the radiometric and biophysical performance of the MODIS vegetation indices. Remote Sens. Environ. 2002, 83, 195-213.

25. Rouse, J.W.; Haas, R.W.; Schell, J.A.; Deering, D.H.; Harlan, J.C. Monitoring the Vernal Advancement and Retrogradation (Greenwave Effect) of Natural Vegetation; NASA/GSFC: Greenbelt, MD, USA, 1974.

26. Helman, D.; Lensky, I.M.; Mussery, A.; Leu, S. Rehabilitating degraded drylands by creating woodland islets: Assessing long-term effects on aboveground productivity and soil fertility. Agric. For. Meteorol. 2014, 195-196, 52-60.

27. Helman, D.; Mussery, A.; Lensky, I.M.; Leu, S. Detecting changes in biomass productivity in a different land management regimes in drylands using satellite derived vegetation index. Soil Use Manag. 2014, 30, 32-39.

28. Rotem-Mindali, O.; Michael, Y.; Helman, D.; Lensky, I.M. The role of local land-use on the urban heat island effect of Tel Aviv as assessed from satellite remote sensing. Appl. Geogr. 2015, 56, 145-153.

29. Levin, N. Human factors explain the majority of MODIS-derived trends in vegetation cover in Israel: A densely populated country in the eastern Mediterranean. Reg. Environ. Chang. 2015, 15, 1-15. 
30. Cleveland, W.S. Robust locally weighted regression and smoothing scatterplots. J. Am. Stat. Assoc. 1979, 74, 829-836.

31. Schaaf, C.B.; Gao, F.; Strahler, A.H.; Lucht, W.; Li, X.; Tsang, T.; Strugnell, N.C.; Zhang, X.; Jin, Y.; Muller, J.-P.; et al. First operational BRDF, albedo nadir reflectance products from MODIS. Remote Sens. Environ. 2002, 83, 135-148.

32. Rotenberg, E.; Yakir, D. Distinct patterns of changes in surface energy budget associated with forestation in the semiarid region. Glob. Chang. Biol. 2011, 17, 1536-1548.

33. Sprintsin, M.; Cohen, S.; Maseyk, K.; Rotenberg, E.; Grünzweig, J.; Karnieli, A.; Berliner, P.; Yakir, D. Long term and seasonal courses of leaf area index in a semi-arid forest plantation. Agric. For. Meteorol. 2011, 151, 565-574.

34. Rotenberg, E.; Yakir, D. Contribution of semi-arid forests to the climate system. Science 2010, 327, 451-454.

35. Ahlström, A.; Raupach, M.R.; Schurgers, G.; Smith, B.; Arneth, A.; Jung, M.; Reichstein, M.; Canadell, J.G.; Friedlingstein, P.; Jain, A.K.; et al. The dominant role of semi-arid ecosystems in the trend and variability of the land $\mathrm{CO}_{2}$ sink. Science 2015, 348, 895-899.

36. Ne'eman, G. Regeneration of natural pine forest - Review of work done after the 1989 fire in Mount Carmel, Israel. Int. J. Wildl. Fire 1997, 7, 295-306.

37. Tessler, N.; Wittenberg, L.; Provizor, E.; Greenbaum, N. The influence of short-interval recurrent forest fires on the abundance of Aleppo pine (Pinus halepensis Mill.) on Mount Carmel, Israel. For. Ecol. Manage. 2014, 324, 109-116.

38. Tessler, N.; Wittenberg, L.; Greenbaum, N. Soil water repellency persistence after recurrent forest fires on Mount Carmel, Israel. Int. J. Wildl. Fire 2013, 22, 515-526.

39. Tessler, N. Documentation and analysis of wildfire regimes on Mount Carmel and the Jerusalem hills. 2012, 79, 184-193.

40. Stohlgren, T.J. Measuring Plant Diversity: Lessons from the Field; Oxford University Press: Oxford, UK, 2007.

41. Neary, D.G.; Ryan, K.C.; DeBano, L.F. Wildland Fire in Ecosystems: Effects of Fire on Soils And Water; Gen. Tech. Rep. RMRS-GTR-42; U.S. Department of Agriculture, Forest Service, Rocky Mountain Research Station: Ogden, UT, USA, 2005; Volume 4, p. 250.

42. Morisette, J.T.; Baret, F.; Privette, J.L.; Myneni, R.B.; Nickeson, J.E.; Garrigues, S.; Shabanov, N.V.; Weiss, M.; Fernandes, R.A.; Leblanc, S.G.; et al. Validation of global moderate-resolution LAI products: A framework proposed within the CEOS land product validation subgroup. IEEE Trans. Geosci. Remote Sens. 2006, 44, 1804-1817.

43. Paruelo, J.M.; Epstein, H.E.; Lauenroth, W.K.; Burke, I.C. ANPP estimates from NDVI for the central grassland region of the United States. Ecology 1997, 78, 953-958.

44. Zeng, X.; Dickinson, R.E.; Walker, A.; Shaikh, M.; DeFries, R.S.; Qi, J. Derivation and evaluation of global 1-km fractional vegetation cover data for land modeling. J. Appl. Meteor. 2000, 39, 826-839.

45. Daly, C.; Bachelet, D.; Lenihan, J.M.; Neilson, R.P.; Parton, W.; Ojima, D. Dynamic simulation of tree-grass interactions for global change studies. Ecol. Appl. 2000, 10, 449-469.

46. Merzer, T. The Effects of Different Vegetative Cover on the Local Hydrological Balance of a Semi Arid Afforestation. Master's Thesis, Ben Gurion University of the Negev, Beer-Sheva, Israel, 2007. 
47. Carmel, Y.; Paz, S.; Jahashan, F.; Shoshany, M. Assessing fire risk using Monte Carlo simulations of fire spread. For. Ecol. Manage. 2009, 257, 370-377.

48. Chakroun, H.; Mouillot, F.; Hamdi, A. Regional equivalent water thickness modeling from remote sensing across a tree cover/LAI gradient in Mediterranean forests of northern Tunisia. Remote Sens. 2015, 7, 1937-1961.

49. Majasalmi, T.; Rautiainen, M.; Stenberg, P.; Manninen, T. Validation of MODIS and GEOV1 fPAR products in a boreal forest site in Finland. Remote Sens. 2015, 7, 1359-1379.

50. Ryu, Y.; Lee, G.; Jeon, S.; Song, Y.; Kimm, H. Monitoring multi-layer canopy spring phenology of temperate deciduous and evergreen forests using low-cost spectral sensors. Remote Sens. Environ. 2014, 149, 227-238.

(C) 2015 by the authors; licensee MDPI, Basel, Switzerland. This article is an open access article distributed under the terms and conditions of the Creative Commons Attribution license (http://creativecommons.org/licenses/by/4.0/). 